\title{
AVALIAÇÃO DA HIGROSCOPICIDADE DE FERTILIZANTES E CORRETIVOS
}

\author{
J.C. ALCARDE'; E. MALAVOLTA ${ }^{2}$; A.L. BORGES ; A.S. MUNIZ ${ }^{3}$; C.A. VELOSO; \\ A.C. FABRfCIO ${ }^{3}$; I. DE J.M. VIEGAS ${ }^{3}$
}

\begin{abstract}
RESUMO: Visando determinar a quantidade de agua absorvida em função da umidade do ambiente e do tempo de exposiç̄o por alguns fertilizantes simples, misturas de fertilizantes e corretivos, foram colocadas em tres ambientes de umidade relativa constante de $70,4 \%, 80,5 \%$ e $88,8 \%$. As amostras foram pesadas ap $6 s$ 0, 3, 6, 24, 48 e 72 horas determinando a porcentagem de agua absorvida. A absorção de agua pelos produtos aumentou com o aumento da umidade relativa do ar e do tempo de exposicão. Todos os materiais absorveram alguma umidade no menor tempo e na menor umidade relativa estudados, isto é, 3 horas de $\mathbf{7 0 , 4 \%}$, porém essa absorção foi insignificante nos casos do sulfato de amonio, fosfato diamonico, fosfato natural parcialmente acidulado, cloreto de potássio, sulfato de potássio, calcário calcinado. Os fertilizantes nitrogenados, uréia e nitrocálcio, foram os que apresentaram maior higroscopicidade dentre os materiais estudados. Foi possível verificar também que a presença de 5\% de calcário calcinado ou de vermiculita nas misturas de grânulos diminuiu sensivelmente sua higroscopicidade.
\end{abstract}

Deacritores: fertilizantes, corretivos, higroscopicidade.

\section{HIGROSCOPICITY EVALUATION OF FERTILIZERS AND AGRICULTURAL LIMING MATERIALS}

ABSTRAC: The percentual of water absorbed by fertilizer materials, bulk blend fertilizer mixtures and agricultural liming materials was determined as a function of the environment relative humidity and time of exposition. Samples of these were exposed to three relative humidity environments: $70,4 \%, 80,5 \%$ and $77,8 \%$, during $3,6,12,24,48,72$ hours, after drying at $50^{\circ} \mathrm{C}$ for 24 hours. The water absorbed by all products increased with air relative humidity and exposition time. All the materials absorbed some humidity for the lowest exposition time and lowest relative humidity ( 3 hours and $70,4 \%$ ) but was insignificant in the case of ammonium sulphate, diammonium phosphate, natural phosphate parcially acidulated, potassium chloride, potassium sulphate, limestone and hidrated lime. The urea and calcium nitrate presented major higroscopicity among the materials studied. The presence of $5 \%$ hidrated lime or vermiculite in bulk blend mixtures decreases significatively the higroscopicity.

Key Words: agricultural fertilizers, higroscopicity, liming materials.

\section{INTRODUÇÃO}

Os adubos ou fertilizantes são encontrados em três estados físicos: sólido, fluído e gasoso. A forma sólida é a mais utilizada no Brasil.

Uma das características físico-químicas muito importante dos fertilizantes ślidos é a sua higroscopicidade, isto $\hat{\epsilon}$, a tendencia em absorver água, normalmente da atmosfera (SAUCHELLI, 1960). É uma característica onde para cada substância ou mistura de substâncias há um máximo de umidade relativa do ambiente (umidade crítica - UC) a que o produto pode ser exposto sem grande absorção de água (ALCARDE et al., 1989).

A umidade crítica da maioria dos fertilizantes e de suas misturas binárias $\varepsilon$ apresentada na Figura 1.

Os fertilizantes de baixa umidade crítica

\footnotetext{
'Departamento de Química da E.S.A. "Luiz de Queiroz" da Universidade de São Paulo, 13418-900-PIRACICABASP.

${ }^{2}$ Centro de Energia Nuclear na Agricultura - CENA/USP, 13418-900-PIRACICABA-SP

${ }^{3}$ Aluno de Pós-Graduação do Curso de Solos e Nutrição de Plantas da ESALQ/USP, 13418-900-PIRACICABA-SP.
} 
possuem alta higroscopicidade, ou seja, absorvem umidade do ar mesmo quando esta é baixa.

Exemplificando, a UC do nitrato de amônio é $59,4 \%$ : isto significa que este fertilizante já absorverá umidade com relativa intensidade quando a umidade relativa do ar for igual ou maior que $59,4 \%$ (ALCARDE et al., 1989).

Fertilizantes úmidos ou os que tendem absorver a água do ar são problemáticos, pois apresentam uma série de inconvenientes: dificuldade de manuseio e de "escoamento" (fluidez), tendência ao empedramento, diminuição no teor de nutrientes, dentre outros.

Nas misturas de substâncias a umidade crítica é a menor que a de cada componente, ou seja, a higroscopicidade é maior, conforme mostra figura 1 (FINCK, 1982; ALCARDE et al., 1989). Não é possível predizer a úmidade crítica das misturas (SAUCHELLI, 1960). Quando a umidade crítica de uma mistura é baixa diz-se que os componentes são incompativeis.

Existem meios de se prevenir ou minimizar os efeitos da higroscopicidade dos fertilizantes, como a granulação (aumento do tamanho do grânulo), o revestimento dos grânulos com certos materiais (exemplo: uréia formaldeído) e boas condições de armazenamento.

Este trabalho teve como objetivos: determinar a quantidade de água absorvida em função da umidade do ambiente e do tempo de exposição pela maioria dos fertilizantes simples e corretivos comercializados no Brasil e estudar meios de minimizar a higroscopicidade de mistura de grânulos.

\section{MATERIAL E MÉTODOS}

O material constou de amostras de fertilizantes simples comerciais, de corretivos de acidez e de duas misturas de granulos. Os fertilizantes simples foram: uréia, sulfato de amônio, nitrato de amônio, nitrocálcio, fosfato monoamônico, fosfato diamônico, superfosfato simples, superfosfato triplo, fosfato natural parcialmente acidulado, cloreto de potássio, sulfato de potássio e magnésio e sulfato de potássio. Os corretivos de acidez foram calcário, cal hidratada e calcário calcinado. Todos os fertilizantes se encontravam na forma granulada exceto o sulfato de amônio, cloreto de potássio, sulfato de potássio e magnésio e sulfato de potássio que se encontravam na forma cristalizada. Os corretivos se encontravam na forma de pó.

As duas misturas de grânulos foram as mais utilizadas no Brasil, isto é, 04-14-08 e 20-05-20 nas seguintes condições: (1) com componentes compatíveis; (2) com componentes reconhecidamente incompatíveis mas com grande produção no Brasil (uréia e superfosfato); (3), (4) e (5) com os componentes reconhecidamente incompatíveis mas com outros componentes objetivando minimizar a higroscopicidade: superfosfatos amoniados, calcário calcinado e vermiculita. Essas misturas estão apresentadas na Tabela 1.

Os ambientes de umidade relativa constante foram obtidos em dessecadores de 200 ou $250 \mathrm{~mm}$ de diâmetro contendo no interior solução de ácido sulfúrico $4,92 \mathrm{~N}$ ou $6,78 \mathrm{~N}$ ou $8,68 \mathrm{~N}$, o que proporciona ambientes de umidade relativa constante de $88,8 \%$, $80,5 \%$ e $70,4 \%$, respectivamente.

As amostras foram colocadas em latinhas de $4 \mathrm{~cm}$ de diâmetro por $1 \mathrm{~cm}$ de altura e de peso conhecido, levadas à estufa a $50^{\circ} \mathrm{C}$ por 24 horas, esfriadas e pesadas. Em seguida foram colocadas nos ambientes de umidade relativa constante $\mathrm{e}$ foram pesadas após $3,6,12,24,48$ e 72 horas. A porcentagem de água absorvida ( $\%$ U) foi calculada em relação ao peso da amostra seca pela expressão:

$$
\begin{aligned}
\mathrm{U}= & {[(\mathrm{Pu}-\mathrm{Ps}) / \mathrm{Ps}] 100, \text { scndo } } \\
& \mathrm{Pu}=\text { peso, em } \mathrm{g}, \text { da amostra úmida } \\
& \mathrm{Ps}=\text { peso, em } \mathrm{g}, \text { da amostra seca }
\end{aligned}
$$

\section{RESULTADOS E DISCUSSÃo}

Os resultados de absorção de umidade pelos fertilizantes simples e corretivos, em cada ambiente de umidade e nos diversos períodos de tempo são mostrados nas tabelas de $n^{\circ} \mathrm{s} 2$ a 4 . Verifica-se que a absorção de umidade pelos materiais testados variou em função do teor de umidade do ambiente, do tempo de exposição do material a determinada umidade e da natureza do fertilizante simples ou do corretivo. Via de regra verificou-se um aumento da umidade absorvida à medida que se aumentou a umidade do ambiente e o tempo da exposição do material a estas umidades.

A umidade absorvida variou amplamente conforme a natureza do material, indo de $0,002 \%$ no caso do sulfato de potássio até $18,46 \%$ no caso da uréia, considerando-se o tempo de 72 horas e a umidade relativa de $88,8 \%$, o que corresponde à máxima umidade (Tabela 4). Este fato demonstra a existência de diferenças nos materiais quando a higroscopicidade (Procedures, 1970; ALCARDE et al., 1989). 
Tabela 1. Composição das misturas de fertilizantes

\begin{tabular}{||cl|}
\hline \multicolumn{1}{|c||}{ Misturas } & \multicolumn{1}{c|}{ Componentes } \\
\hline $4-14-8(1)$ & $\mathrm{SA}+\mathrm{SS}+\mathrm{KCl}$ \\
$4-14-8(2)$ & Uréia $+\mathrm{SS}+\mathrm{KCl}$ \\
$4-14-8(3)$ & Uréia $+\mathrm{SS}$ (amoniado) $\mathrm{KCl}+$ pirofilita \\
$4-14-8(4)$ & Uréia $+\mathrm{SS}+\mathrm{ST}+\mathrm{KCl}+$ calcário calcinado (5\%) \\
$4-14-8(5)$ & Uréia $+\mathrm{SS}+\mathrm{ST}+\mathrm{KCl}+$ vermiculita (5\%) \\
$20-5-20(1)$ & Uréia $+\mathrm{DAP}+\mathrm{KCl}+$ pirofilita \\
$20-5-20(2)$ & Uréia $+\mathrm{SS}+\mathrm{ST}+\mathrm{KCl}$ \\
$20-5-20(3)$ & Uréia $+\mathrm{SS}(\mathrm{amoniado})+\mathrm{ST}$ (amoniado) + KCl \\
$20-5-20(4)$ & Uréia $+\mathrm{SS}+\mathrm{ST}+\mathrm{KCl}+$ calcário calcinado (5\%) \\
$20-5-20(5)$ & Uréia $+\mathrm{SS}+\mathrm{ST}+\mathrm{KCl}+$ vermiculita (5\%) \\
\hline
\end{tabular}

SA = sulfato de amônio; $S S$ = superfosfato simples; $S T$ = superfosfato triplo

Tabela 2. Umidade absorvida pelos materiais, expressa em \%, em função do tempo, expostos na umidade relativa de $70,4 \%$.

\begin{tabular}{||lccccc||}
\hline \multicolumn{1}{|c}{ Materiais } & \multicolumn{5}{c}{ Tempo de exposição (horas) } \\
\cline { 2 - 6 } & 3 & 6 & 24 & 48 & 72 \\
\hline Uréia & 0,38 & 0,66 & 2,39 & 4,47 & 6,12 \\
Sulfato de amônio & 0,03 & 0,03 & 0,04 & 0,05 & 0,06 \\
Nitrato de amônio & 0,08 & 0,16 & 0,31 & 1,08 & 1,80 \\
Nitrocálcio & 0,31 & 0,38 & 0,84 & 1,42 & 2,00 \\
Fosfato monoamônico & 0,11 & 0,26 & 0,86 & 1,15 & 1,27 \\
Fosfato diamónico & 0,16 & 0,20 & 0,32 & 0,36 & 0,37 \\
Superfosfato simples & 0,13 & 0,22 & 0,57 & 0,71 & 0,76 \\
Superfosfato triplo & 0,17 & 0,30 & 0,67 & 0,87 & 0,89 \\
Fosfato parcialmente acidulado & 0,15 & 0,20 & 0,31 & 0,32 & 0,33 \\
Cloreto de potássio & 0,03 & 0,04 & 0,10 & 0,12 & 0,13 \\
Sulfato de potássio e magnésio & 0,25 & 0,35 & 0,84 & 1,00 & 1,22 \\
Sulfato de potássio & 0,001 & 0,002 & 0,002 & 0,002 & 0,003 \\
Calcário & 0,10 & 0,14 & 0,21 & 0,21 & 0,21 \\
Cal hidratada & 0,06 & 0,09 & 0,23 & 0,29 & 0,30 \\
Calcário calcinado & 0,13 & 0,18 & 0,62 & 1,28 & 1,86 \\
\hline \hline
\end{tabular}


Tabela 3. Umidade absorvida pelos materiais, expressa em \%, em função do tempo, expostos na umidade relativa de $80,5 \%$

\begin{tabular}{|lccccc||}
\hline \multicolumn{1}{c}{ Materiais } & \multicolumn{5}{c}{ Tempo de exposição (horas) } \\
\cline { 2 - 6 } & 3 & 6 & 24 & 48 & 72 \\
\hline Uréia & 0,64 & 1,17 & 4,70 & 8,91 & 12,41 \\
Sulfato de amônio & 0,04 & 0,05 & 0,10 & 0,13 & 0,14 \\
Nitrato de amônio & 0,10 & 0,24 & 0,63 & 2,16 & 3,21 \\
Nitrocálcio & 0,42 & 0,57 & 1,54 & 3,17 & 3,31 \\
Fosfato monoamônico & 0,14 & 0,34 & 1,17 & 1,54 & 1,61 \\
Fosfato diamônico & 0,15 & 0,19 & 0,37 & 0,47 & 0,51 \\
Superfosfato simples & 0,16 & 0,27 & 0,73 & 0,92 & 0,97 \\
Superfosfato triplo & 0,24 & 0,43 & 0,97 & 1,26 & 1,31 \\
Fosfato parcialmente acidulado & 0,18 & 0,22 & 0,35 & 0,36 & 0,36 \\
Cloreto de potássio & 0,03 & 0,05 & 0,17 & 0,27 & 0,37 \\
Sulfato de potássio c magnésio & 0,25 & 0,42 & 1,12 & 2,31 & 3,36 \\
Sulfato de potássio & 0,002 & 0,003 & 0,004 & 0,004 & 0,008 \\
Calcário & 0,12 & 0,15 & 0,21 & 0,21 & 0,22 \\
Cal hidratada & 0,08 & 0,12 & 0,30 & 0,35 & 0,37 \\
Calcário calcinado & 0,19 & 0,42 & 0,99 & 2,03 & 2,74 \\
\hline
\end{tabular}

Considerando-se a umidade crítica dos fertilizantes verificou-se que houve maior quantidade de água absorvida à medida que aumentou a diferença entre a umidade relativa do ar e a umidade crítica do fertilizante, sendo este efeito mais expressivo com o aumento do tempo de exposição como pode ser verificado no caso da uréia, sulfato de amônio, nitrato de amônio, DAP e KC1.

A partir do conceito de umidade crítica (T.V.A. 1970; ALCARDE et al., 1989), tem-se que o fertilizante que apresentou absorção de umidade considerada nula, ou seja, valores de milesimos de porcentuais até o tempo de 72 horas, foi o sulfato de potássio, cuja umidade crítica do sal fertilizante $\epsilon^{\prime}$ $96,3 \%$, portanto bem acima dos valores de umidade relativa usados neste trabalho.

Os fertilizantes nitrogenados uréia, nitrato de amônia e nitrocálcio mostraram-se os mais higroscópicos dos adubos, apresentando absorção de umidade crescente em função da umidade relativa e do tempo,assim como os maiores valores de água absorvida. A absorção de água pela uréia $(\mathrm{UC}=$ $\mathbf{7 5 , 2 \% )}$ no ambiente de umidade relativa de $\mathbf{7 0 , 4 \%}$, provavelmente deveu-se a impurezas no adubo, o que contribui para a diminuição da UC (ALCARDE et al., 1989).

Os adubos fosfatados e potássicos mostraram-se bem menos higroscópicos que os adubos nitrogenados, excessão feita ao K-Mag.

Entre os adubos potássicos verifica-se com nitidez a relação que existe entre a umidade crítica do fertilizante e a umidade relativa do ar na absorção de umidade pelo fertilizante, como pode ser visto com o adubo sulfato de potássio (UC $=96,3 \%$ ). $O$ adubo $\mathrm{K}$ Mag $\left(\mathrm{K}_{2} \mathrm{SO}_{4} \cdot \mathrm{MgSO}_{4}\right)$ apresentou valores de absorção crescentes situando-se entre $0,25 \%$ e $4,71 \%$ bem superior a do $\mathrm{K}_{2} \mathrm{SO}_{4}$.

Os corretivos apresentaram comportamento 
Tabela 4. Umidade absorvida pelos materiais, expressa em \%, em função do tempo, expostos na umidade relativa de $88,8 \%$.

\begin{tabular}{||lccccc||}
\hline \multicolumn{1}{c}{ Materiais } & \multicolumn{5}{c||}{ Tempo de exposicão (horas) } \\
\cline { 2 - 6 } & 3 & 6 & 24 & \multicolumn{1}{c||}{48} & 72 \\
\hline Uréia & 0,82 & 1,56 & 6,47 & 12,65 & 18,46 \\
Sulfato de amônio & 0,07 & 0,10 & 0,42 & 1,03 & 1,04 \\
Nitrato de amônio & 0,14 & 0,29 & 1,59 & 4,23 & 6,47 \\
Nitrocálcio & 0,57 & 0,89 & 3,13 & 6,18 & 9,55 \\
Fosfato monoamônico & 0,18 & 0,43 & 1,36 & 1,64 & 1,80 \\
Fosfato diamônico & 0,31 & 0,40 & 1,11 & 1,34 & 1,73 \\
Superfosfato simples & 0,19 & 0,34 & 0,89 & 1,08 & 1,16 \\
Superfosfato triplo & 0,26 & 0,48 & 1,20 & 1,56 & 1,67 \\
Fosfato parcialmente acidulado & 0,30 & 0,38 & 0,66 & 0,66 & 0,73 \\
Cloreto de potássio & 0,07 & 0,09 & 0,38 & 0,91 & 1,42 \\
Sulfato de potássio e magnésio & 0,29 & 0,49 & 2,18 & 3,27 & 4,71 \\
Sulfato de potássio & 0,002 & 0,007 & 0,009 & 0,02 & 0,03 \\
Calcário & 0,12 & 0,17 & 0,21 & 0,22 & 0,23 \\
Cal hidratada & 0,09 & 0,14 & 0,33 & 0,38 & 0,41 \\
Calcário calcinado & 0,45 & 0,46 & 1,52 & 2,89 & 3,51 \\
\hline
\end{tabular}

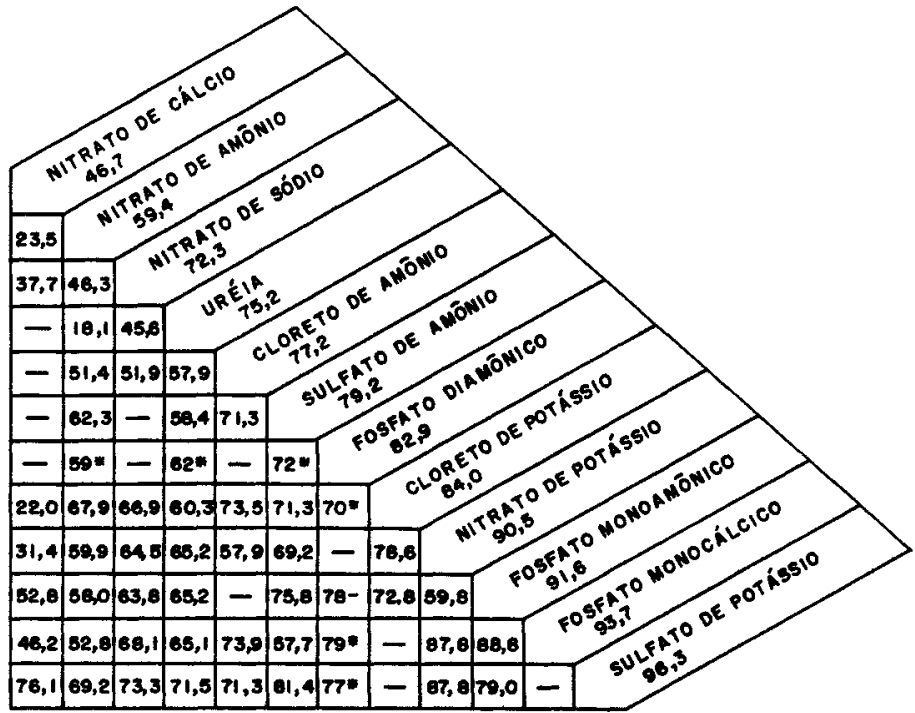

Fig. 1 - Umidades críticas de sais fertilizantes e misturas a $30^{\circ} \mathrm{C}$. Os valores são em $\%$ de umidade relativa. Valores aproximados obtidos pelo T.V.A. (TVA, 1970). 


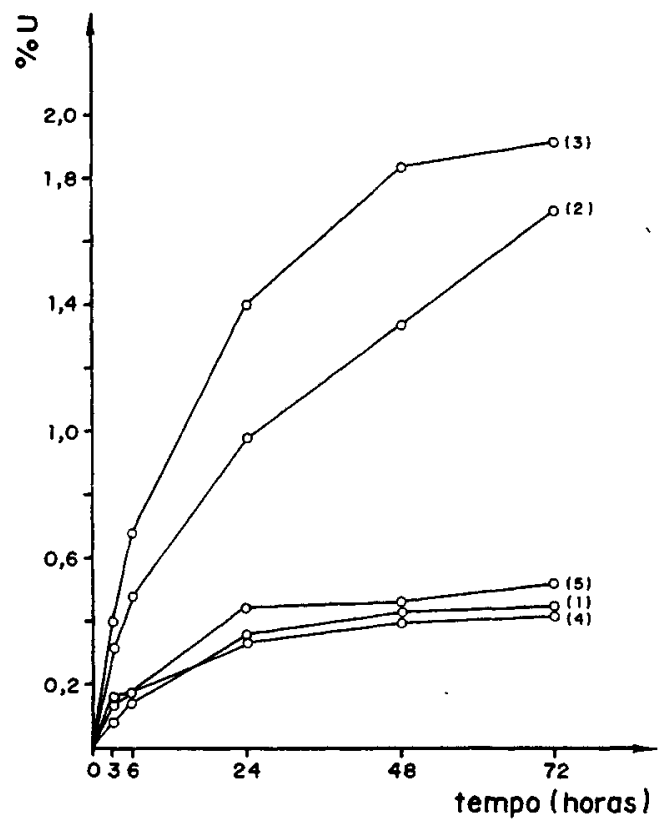

Fig. 2 - Teor de água absorvida (\%U) em relação ao tempo pela fórmula 4-14-8 com cinco composições diferentes, na umidade relativa de $70,4 \%$.

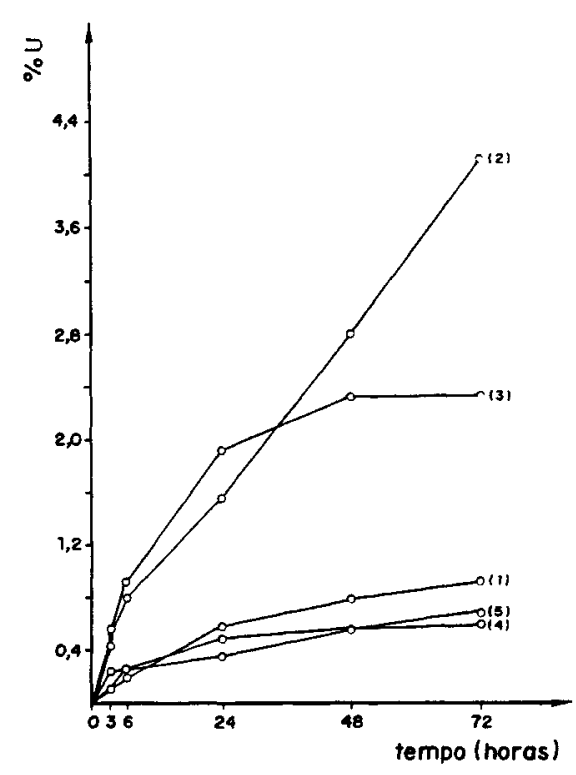

Fig. 3 - Teor de agua absorvida (\%U) em relação ao tempo pela fórmula 4-14-8 com cinco composições diferentes, na umidade relativa de $80,5 \%$.

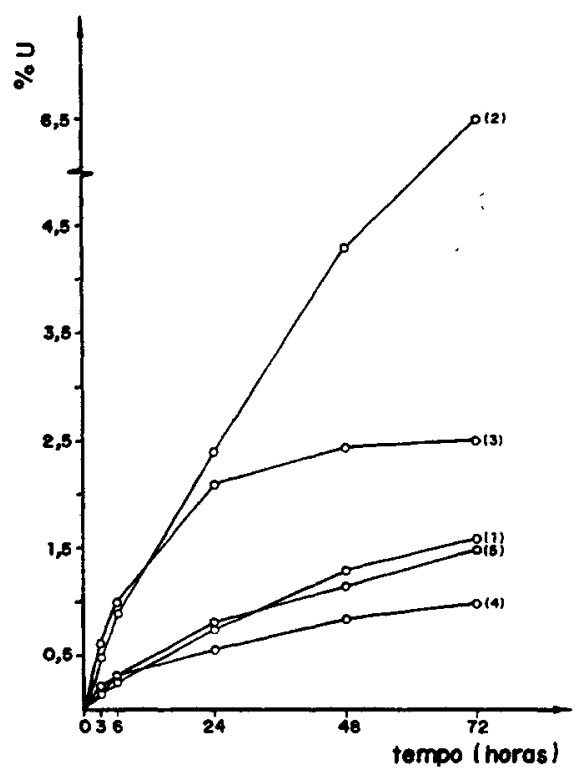

Fig. 4 - Teor de água absorvida (\%U) em relação ao tempo pela fórmula 4-14-8 com cinco composições diferentes, na umidade relativa de $88,8 \%$

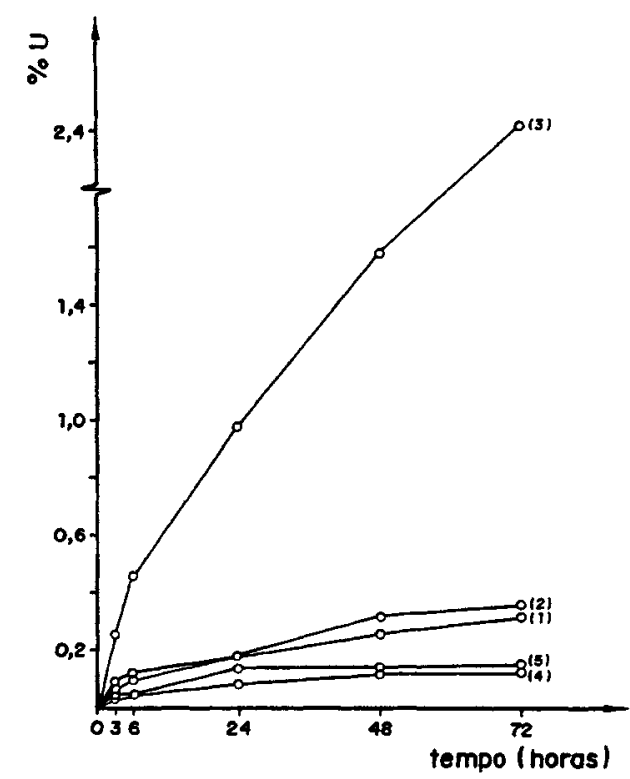

Fig. 5 - Teor de água absorvida (\%U) em relação ao tempo pela formula $20-5-20 \mathrm{com}$ cinco composições diferentes, na umidade relativa de $70,4 \%$. 


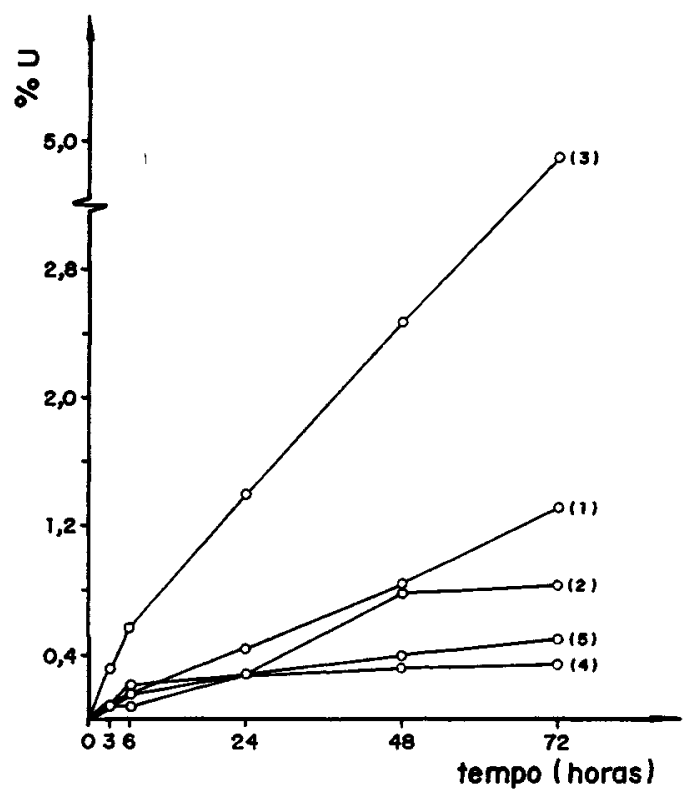

Fig. 6 - Teor de água absorvida (\%U) em relação ao tempo pela fórmula $20-5-20$ com cinco composições diferentes, na umidade relativa de $80,5 \%$.

diferenciado em relação a absorção de água menor absorção foi mostrada pela cal hidratada $(0,41 \%)$ e a maior absorção pelo calcário calcinado $(3,51 \%)$, considerando-se o tempo de 72 horas e $88,5 \%$ de umidade relativa.

Em relação às misturas também ocorreu aumento de água absorvida em função do aumento da umidade da água do ambiente e do tempo de exposição.

A conhecida incompatibilidade entre a uréia e os superfosfatos ficou bem evidente na mistura 04-1408 (2), o mesmo não ocorrendo na mistura 20-05-20 (2) (Figuras 2 e 7).

Por outro lado, o superfosfato amoniado diminuiu a higroscopicidade da mistura 04-14-08 (3) e, surpreendentemente, comportou-se de maneira inversa na mistura 20-05-20 (3), isto $\hat{e}$, nesta sua presença aumentou sensivelmente a higroscopicidade da mistura.

Os componentes calcário calcinado e vermiculita mostraram-se altamente eficientes na prevenção de higroscopicidade nas duas misturas estudadas, proporcionando higroscopicidade das misturas tidas como incompativeis, menor que a higroscopicidade das misturas originais tidas como compatíveis.

\section{CONCLUSÕES}

A água absorvida pelos fertilizantes e corretivos, num mesmo tempo de exposição, foi maior quando se aumentou a umidade relativa do ambiente. A umidade absorvida de cada ambiente foi mais alta com o maior tempo de exposição.

Com excessão do sulfato de potássio $\left(\mathrm{K}_{2} \mathrm{SO}_{4}\right)$, os demais materiais absorveram pouca

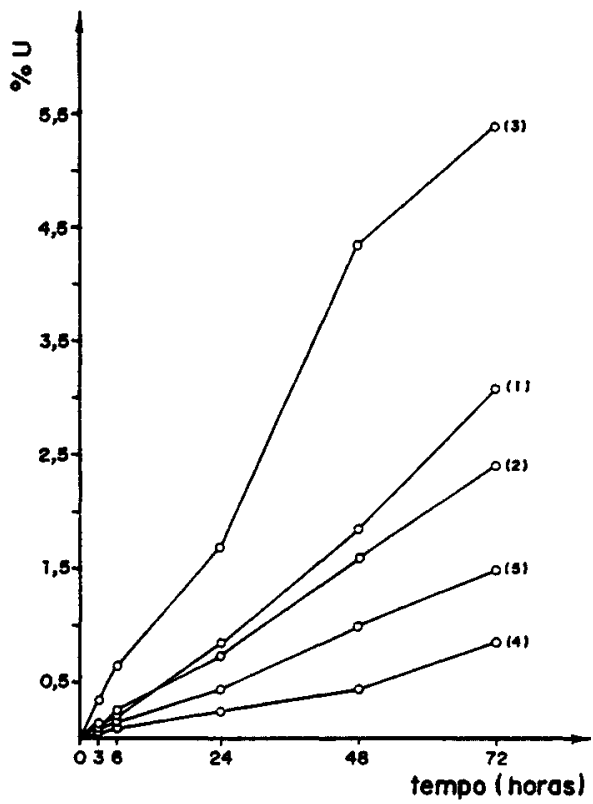

Fig.7 - Teor de água absorvida (\%U) em relação ao tempo pela fórmula $20-5-20$ com cinco composições diferentes, na umidade relativa de $\mathbf{8 8 , 8 \%}$.

água no tempo de três horas de umidade relativa de $70,4 \%$ (menor tempo de exposição e menor umidade estudados). Os fertilizantes nitrogenados simples, uréia e nitrocálcio, foram os que apresentaram maior higroscopicidade dentre os materiais estudados.

O calcário calcinado e a vermiculita podem minimizar a higroscopicidade de misturas de grânulos de fertilizantes, inclusive entre os componentes tidos como incompatíveis, como é o caso da uréia com superfosfato. Isso permite fazer maior uso dos fertilizantes uréia e superfosfato tripo, que são os de menor custo unitário dos nutrientes, $N$ e $P$, respectivamente.

\section{AGRADECIMENTOS}

Aos colegas que cursaram a disciplina LQI810-Avaliação de Fertilizantes e Corretivos, no $2^{\circ}$ semestre de 1990, pelo auxílio na coleta dos dados de umidade.

\section{REFERÊNCIAS BIBLIOGRÁFICAS}

ALCARDE, J.C.; GUIDOLIN, J.A.; LOPES, A.S. Os adubos e a eficiencia das adubaçōes. São Paulo, Anda, 1989. 35p. (Boletim Técnico,3)

FINCK, A. Fertilizers and fertilization; introduction and pratical guide to fertilization. Weinheim, Verlag. Chemie, 1982. 438p.

SAUCHELLI, V., ed. Chemistry and technology of fertilizers. New York, Reinhold, 1960. 692p. 
T.V.A. Procedures for determinning physical properties of fertilizers. Special Repor n. 5.444. September, 1970. 17p, Tennessee Valley Authority, Mucle Shoals, Alabama, USA.

Trabalho entregue para publicação em 17.12.91

Trabalho aprovado para publicação em 12.03.92 